\title{
LA INVIOLABILIDAD DEL DOMICILIO
}

\author{
$342.4(46)$
}

por

\section{Lorenzo Plaza Arrimadas}

Vicesecretario del Excmo. Ayuntamiento de Alicante

SUMARIO: I. INTRODUCCION.-II. CASOS DE ENTRADA LEGAL EN EL DOMICILIO AJENO: 1. CUANDO SE CUENTE CON EL CONSENTIMIENTO DEL TITULAR. 2. EN CASO DE FLAGRANTE DELITO. 3. CUando SE CUENTE CON UNA RESOlUCión Judicial QUE lo aUtoRICE. 4. EN LOS CASOS DE GRAVE RIESGO, CATÁSTROFE O CALAMIDAD PÚBLICA. 5. CUANDO SE DECLARE EL ESTADO DE EXCEPCIÓN O DE SITIO O LA GUERRA. 6. EN LOS CASOS DE ACTUACIÓN DE BANDAS ARMADAS O ELEMENTOS TERRORISTAS. 7. ¿PARA PROTEGER EL LIBRE EJERCICIO DE LOS DERECH OS Y LIBERTADES Y GARANTIZAR LA SEGURIDAD CIUDADANA?-III. PROCEDIMIENTO A SEGUIR PARA OBTENER LA AUTORIZACION JUDICIAL: 1. SUPUESTOS EN QUE SE EXIGE LA RESOLUCIÓN JUDICIAL. 2. AMPLIACIÓN CONSTITUCIONAL DE LAS FUNCIONES DE LOS ÓRGaNoS JUdiciales. 3. ORgaNos JUdiciales COMPETENTES. 4. Procedimiento JUdicial. 5. NATURAleza, ObliGATORIEDAD Y SENTIDO DE LA RESOLUCIÓN. 6. RECURSOS Y OTROS REMEDIOS.-IV. RESPONSABILIDADES DERIVADAS DE LA VIOLACION DEL DOMICILIO AJENO: 1. RESPONSABILIDAD PENAL. 2. OTRAS RESPONSABILIDADES.-V. PROCEDIMIENTOS LEGALES ESTABLECIDOS PARA GARANTIZAR LA INVIOLABILIDAD DEL DOMICILIO.-VI. ANEXO. 


\section{INTRODUCCION}

El derecho a la inviolabilidad del domicilio ajeno es el que se reconoce a su titular para que pueda exigir que nadie entre o efectúe registro en él por la fuerza, es decir, sin su consentimiento. (En lo sucesivo, en aras de la brevedad, omitiremos la alusión al registro).

En principio, pues, nadie tiene derecho a penetrar en el domicilio ajeno. A continuación vamos a estudiar las posibles excepciones a esta regla general, sin detenernos a considerar si la concurrencia de los elementos o circunstancias exigidos para ello producirán el efecto de hacer desaparecer la auténtica existencia de la violación de domicilio o solamente las responsabilidades derivadas del hecho.

\section{CASOS DE ENTRADA LEGAL EN EL DOMICILIO AJENO}

La inviolabilidad del domicilio es uno de los derechos fundamentales reconocidos como tales por nuestra Constitución y, por tanto, de ella hemos de partir en nuestros planteamientos. La proclamación de este derecho se hace en el artículo 18, 2, de la Constitución. Pero antes de estudiar su contenido, considerado en sí mismo, parece conveniente hacerlo, para una más fácil comprensión, en relación con el de su más inmediato precedente en el tiempo, el del artículo 15 del Fuero de los Españoles, hoy derogado. Los preceptos citados dicen así:

- Artículo 15 del Fuero de los Españoles, de 17 de julio del año 1945:

«Nadie podrá entrar en el domicilio de un español ni efectuar registros en él sin su consentimiento, a no ser con mandato de la autoridad competente y en los casos y en la forma que establezcan las leyes».

- Artículo 18, 2, de la Constitución española, aprobada por las Cortes el 31 de octubre de 1978:

«El domicilio es inviolable. Ninguna entrada o registro podrá hacerse en él sin consentimiento del titular o resolución judicial, salvo en caso de flagrante deliton.

En ambos artículos se parte del mismo principio: no se puede entrar ni hacer registro en el domicilio ajeno sin el consentimiento 
de su titular. Sin embargo, de la simple comparación literal se advierten varias diferencias, algunas de ellas, a nuestro juicio, esenciales. Por ejemplo:

1. El Fuero de los Españoles limita la prohibición a la entrada en el domicilio de un "español", lo que no se hace en la Constitución de 1978. También los extranjeros pueden tener su domicilio en España.

2. ${ }^{\mathrm{a}}$ Los supuestos en que se permite la entrada o el registro, sin el consentimiento del titular del domicilio, son distintos:

El Fuero de los Españoles lo permite cuando se cuente «con mandato de la autoridad competente y en los casos y en la forma que establezcan las leyes».

La Constitución de 1978 sólo lo autoriza (salvo en caso de flagrante delito) cuando se cuente con una resolución judicial.

Veamos ahora los supuestos en que se permite la entrada en el domicilio ajeno.

1. CuANDo SE CUENTE CON EL CONSENTIMiento DEL TITUlaR (artículo 18, 2, de la Constitución)

Ninguna novedad aporta en este aspecto la Constitución de 1978. Por esta razón no vamos a tratar aquí de dilucidar quién es el titular del domicilio, quiénes los demás moradores (que no pueden dar el consentimiento en contra del titular), qué formas de dar el consentimiento se admiten (la doctrina distingue los consentimientos expresos, tácitos y presuntos). Para el estudio de estos puntos, como para el del concepto de domicilio o morada, nos remitimos a la doctrina anterior a la Constitución, que es plenamente aplicable.

\section{EN CASO DE FLAGRANTE DELTTO} (artículo 18, 2, de la Constitución)

También nos remitimos a la doctrina anterior respecto al concepto de delito in fraganti y a las circunstancias que han de concurrir con la comisión del delito para justificar la entrada en el domicilio de otro. 
3. CUANDO SE CUENTE CON UNA RESOLUCIÓN JUDICIAL QUE LO AUTORICE (art. 18, 2, de la Constitución)

En contra de lo que podría deducirse del artículo 18, 2, de la Constitución, no es necesario - ni sería correcto, ni práctico- solicitar la resolución judicial en todos los casos en que se desee entrar en el domicilio de una persona y no se cuente con el consentimiento de su titular, ni se esté cometiendo un delito. Entendemos que la resolución judicial no se ha de solicitar y dictar más que con carácter subsidiario, es decir, a falta de la presencia de cualquier otro supuesto justificativo previsto legalmente.

Más tarde, cuando hayamos visto los demás, al tratar del procedimiento a seguir para obtener la autorización judicial, examinaremos más detenidamente todas las cuestiones que plantea.

\section{EN los Casos de GRAVE RIESGo, CATÁstrofe o CALAMIDAD PÚBLICA (art. 30, 4, de la Constitución)}

Ya hemos indicado que el artículo 18, 2, que es el que proclama la inviolabilidad del domicilio, ha previsto también algunos supuestos en que se puede entrar en el domicilio de otro sin su consentimiento. Pero los supuestos del artículo 18, 2, no son los únicos que prevé la Constitución. Si así fuera no se podría desenvolver normalmente la sociedad y se producirían males mucho mayores que con la violación del domicilio de una persona. Imaginemos, como ejemplo, un incendio o la inundación de un edificio que, por las circunstancias que concurren, no permite la salida o el rescate de quienes se hallan en su interior más que a través del domicilio de un colindante. Resultaría incomprensible - a falta de consentimiento del titular del domicilio limítrofe o de flagrante delito- exigir la pasividad de las personas dispuestas a intervenir para intentar salvar la vida de las presuntas víctimas hasta que se obtuviera la resolución judicial pertinente. Hay que procurar hacer compatibles los diversos derechos fundamentales, pero cuando entran en colisión, como en el supuesto examinado, el derecho a la inviolabilidad del domicilio de una persona y el derecho a la vida de otras, alguno ha de ceder: justamente, el que ocupe un rango inferior en la escala de valores de la sociedad.

La rigurosidad de la redacción del artículo 18, 2, de la Constitución queda suavizada, evidentemente, por la afirmación del artículo 10,2 , de que «las normas relativas a los derechos fundamentales 
y a las libertades que la Constitución reconoce se interpretarán de conformidad con la Declaración Universal de Derechos Humanos». Pero no podemos olvidar el carácter meramente interpretativo de esta norma y la prevalencia de nuestra Constitución, en España, cuando se produzca la contradicción entre ambas.

Existe otro artículo en la Constitución, el 30, 4, objeto de nuestra atención en este momento, que ayudará a delimitar el contenido del artículo 18, 2, y a flexibilizar los principios tan rigurosos allí mantenidos.

El citado artículo 30,4 , dice que «mediante ley podrán regularse los deberes de los ciudadanos en los casos de grave riesgo, catástrofe o calamidad pública».

Lo que el artículo 30,4, de la Constitución nos ofrece para que no resulte inviable la aplicación aislada del artículo 18,2 , en sus propios y absolutos términos, es lo siguiente:

1. Permite que se regulen deberes de los ciudadanos. Estos deberes convertirían en jurídicas actuaciones contrarias al artículo 18, 2. Así lo exigiría una interpretación conjunta de la Constitución, como un texto unitario. Advirtamos, sin embargo, que el artículo 30 , 4 , no obliga a los legisladores a dictar estas normas. "Podrán» hacerlo. La oportunidad de efectuarlo queda a su arbitrio, a pesar de tratarse de casos de grave riesgo, catástrofe o calamidad pública.

2. Podrán regularse los «deberes». Los hipotéticos ciudadanos que estén dispuestos a intentar liberar a quienes peligren precisarán, si han de entrar en el domicilio de una persona, actuar en cumplimiento de un «deber», para que las leyes que se dicten en desarrollo del artículo 30, 4, contrarresten la antijuridicidad que, en principio, se atribuye a los infractores del artículo 18,2 . No bastará, para ello, pues, que actúen en el ejercicio de un "derecho», porque el artículo 30,4 , habla de deber, y es claro que cabe el ejercicio de un derecho sin estar cumpliendo simultáneamente un deber.

3. El artículo 30, 4, habla de leyes que regulen los deberes de los «ciudadanos». ¿Significa ello que las leyes que regulen los deberes de las autoridades y funcionarios públicos en general no legitimarán su actuación? Eso nos parece falto de lógica y racionalidad.

Preferimos considerar a dichas autoridades y funcionarios, para no llegar al absurdo, como ciudadanos cualificados por el cargo o la función. No encontramos otra forma de legitimar la actuación de un policía o un bombero en acto de servicio (a las órdenes de sus mandos, con uniforme y vehículos o instrumental de la Administra- 
ción) cuando interviene en una operación de salvamento para evitar un grave riesgo, catástrofe o calamidad pública o disminuir sus efectos. La espera a la obtención de la resolución judicial puede ser decisiva en relación con los males que se pretende prevenir o reducir.

4. Ciertamente, el artículo 30,4 , sólo exige que la regulación se haga mediante ley. Pero también es cierto que esta ley, en cuanto pretenda contraponerse a las que regulen los derechos fundamentales - y el de la inviolabilidad del domicilio es un derecho fundamental-, habrá de tener, como éstas, de conformidad con el artículo 81, 1 , el carácter de ley orgánica.

Las leyes anteriores a la Constitución que regulaban esta materia, no obstante, continuarán vigentes, en cuanto no se opongan, ni a su articulado, ni a sus principios, si bien la interpretación deberá hacerse atendiendo al espíritu que la informa y anima.

5. Cuando SE declare El ESTAdo dE EXCEPCión o de Sitio O DE GUERRA (art. 55, 1, de la Constitución)

El artículo 55, 1, de la Constitución, sin perjuicio del cumplimiento necesario de los requisitos establecidos en el artículo 116, prevé la posibilidad de la suspensión -entre otros- del derecho de inviolabilidad del domicilio, cuando se acuerde la declaración del estado de excepción o de sitio.

La Ley Orgánica número 4, de 1 de junio de 1981, que contiene las normas reguladoras de los estados de alarma, excepción y sitio, en sus artículos 17,1 y 2 , y 32, 3, admite que la autoridad gubernativa podrá disponer inspecciones y registros domiciliarios y llevarlos a cabo ella misma personalmente o a través de sus agentes durante los estados de excepción o de sitio. Entendemos que, con mayor razón, le estará permitido cuando se haya declarado la guerra.

\section{EN LOS CASOS DE ACTUACIÓN DE BANDAS ARMADAS O ELEMENTOS TERRORISTAS (art. 55, 2, de la Constitución)}

El articulo 55, 2, se refiere a otro supuesto de posible suspensión del derecho de inviolabilidad del domicilio, ahora en relación con las investigaciones correspondientes a la actuación de bandas arma- 
das o elementos terroristas; pero, en este caso, con la obligada intervención judicial y el adecuado control parlamentario.

La Ley Orgánica número 11, de 1 de diciembre de 1980, desarrolló este precepto. En ella - artículos $2 .^{\circ}$ y $4 .^{\circ}$, especialmente- se faculta a los miembros de los Cuerpos y Fuerzas de Seguridad del Estado para proceder, sin necesidad de autorización o mandato judicial previo, a la inmediata detención de los presuntos responsables de las acciones a que se refiere el artículo $1 .^{\circ}$, cualquiera que sea el domicilio donde se oculten o refugien, lo que obviamente implica la entrada en el mismo.

\section{7. ¿PARA PROTEGER El LIBRE EJERCICIO DE LOS DERECHOS Y LIBERTADES Y GARANTIZAR LA SEGURIDAD CIUDADANA? (artículo 104 de la Constitución)}

Prescindimos ahora de los miembros de las bandas armadas que inciden en la seguridad ciudadana, a que se refiere el citado artículo $1^{\circ}$ de la Ley Orgánica número 11/1980.

A nuestro juicio, para que la entrada de las Fuerzas y Cuerpos de Seguridad en el domicilio de una persona, para cumplir la misión a que se refiere este punto, pueda considerarse legal, se necesita una resolución judicial previa que lo autorice.

Como acabamos de ver en el supuesto de actuación de bandas armadas o elementos terroristas, cuando nuestros constituyentes han deseado facultar a los Cuerpos y Fuerzas de Seguridad para entrar en domicilio ajeno lo han hecho constar expresamente. Por otra parte, las normas limitativas de derechos - y más de los fundamentales- han de interpretarse restrictivamente.

En el Acuerdo del Consejo de Ministros de 4 de septiembre de 1981, sobre principios básicos de actuación de los miembros de las Fuerzas y Cuerpos de Seguridad del Estado, cuya publicación se dispuso por Orden de 30 del mismo mes, no se recoge ninguno del que pudiera deducirse la facultad de entrar en morada ajena sin previa autorización judicial. Por lo demás, si se hubiera recogido, habría que haberlo considerado anticonstitucional, por carecer dicha Orden del rango de Ley Orgánica exigido por el artículo 104, 2, lo que ha inducido a algunos a negar validez a esa norma aun con la reducción que ha aparecido y el carácter de provisionalidad proclamado expresamente. 


\section{PROCEDIMIENTO A SEGUIR PARA OBTENER LA AUTORIZACION JUDICIAL}

Muchas cuestiones pueden plantearse en relación con este tema. Trataremos todas las que consideramos relevantes.

\section{SUPUESTOS EN QUE SE EXIGE LA RESOLUCIÓN JUDICIAL}

Antes de la Constitución de 1978, y a los efectos que aquí interesan, las leyes que aludían a la entrada en un domicilio ajeno podían distribuirse en tres grupos:

1. Las que declaraban la ejecutoriedad de los actos administrativos o la acción de oficio de la Administración. Ejemplo: Ley de Procedimiento administrativo de 17 de julio de 1958, artículo 102, y Ley de Régimen local, Texto refundido de 24 de junio de 1955, artículo 361 .

2. Las que reconocían, expresamente, a la Administración la facultad de entrar en el domicilio de una persona sin necesidad de la autorización judicial previa. Ejemplo: Ley 45, de 30 de julio de 1959, de Orden Público, artículo 11.

3. Las que exigían a la Administración la resolución judicial. Los ejemplos únicos o verdaderamente importantes, y que examinaremos más tarde con algún detenimiento, son los siguientes (en el Anexo final se transcriben para facilitar su consulta):

- Ley de Enjuiciamiento criminal, artículo 546.

- Ley 230, General Tributaria, de 28 de diciembre de 1963, artículo 130.

- Decreto 3154, de 14 de noviembre de 1968, por el que se aprueba el Reglamento General de Recaudación de Contribuciones e Impuestos, artículo 103; y

- Decreto 2166, de 16 de julio de 1964, Texto de la Ley de Contrabando, adaptado a la General Tributaria, artículos 40, 3, y 41.

La mayor parte de la doctrina admitió la facultad de la Administración (autoridades gubernativas y sus agentes) para actuar, sin autorización judicial, en los supuestos previstos en las leyes del grupo $1 .^{\circ}$, porque esta solución se ajustaba a los principios de eficacia 
exigidos al Ejecutivo y por las fórmulas amplias y generales expresadas en los preceptos que lo regulaban. Así, el citado artículo 102 de la Ley de Procedimiento administrativo se manifiesta en favor de la actuación directa de la Administración, «salvo cuando por ley se exija la intervención de los Tribunales". Ya hemos visto que esta exigencia ha sido reconocida en algunos textos legales concretos.

La Constitución de 1978 ha reducido, como se ha indicado en el epígrafe precedente, los casos en que se puede entrar en la morada ajena sin la autorización judicial.

La Disposición derogatoria de la Constitución de 1978, en su número 3, dice que quedan derogadas cuantas disposiciones se opongan a lo establecido en ésta, y es claro que se oponen a la misma cuantas normas permiten la entrada en el domicilio ajeno con el simple mandato de una autoridad no judicial, salvo en los casos reseñados anteriormente. Por ello, y a pesar de los problemas que las lagunas legales puedan plantear, no cabe admitir la vigencia de las normas que se oponen abiertamente a la Constitución, ni aun interpretándolas conforme al contexto de dicha Ley suprema.

\section{AMPLIACIÓN CONSTITUCIONAL DE LAS FUNCIONES DE LOS ÓRGANOS JUDICLALES}

Con la iniciación de la vigencia de la Constitución quedaron derogadas cuantas normas anteriores se oponían a aquélla, y, por tanto, las que permitían la entrada en el domicilio de las personas con mandato de una autoridad gubernativa, en los casos en que la Constitución ahora exige una resolución judicial previa. Entre otros, podemos citar los de la entrada en una vivienda por motivos de orden público, expropiación, infracción urbanística, ruina normal, etc.

En todos estos casos la Constitución ha respetado integramente el ámbito de las funciones de la Administración, la cual está obligada a ejercitarlas en cuanto el bien de la comunidad lo exija. Se trata de una potestad que abarca tanto el derecho como la obligación de actuar. Lo único que la Constitución ha hecho ha sido condicionar el ejercicio legítimo de esa potestad al cumplimiento previo de un requisito: obtener una autorización judicial para la entrada en el domicilio ajeno.

La aplicación de los preceptos de la Constitución es inmediata en general. La de las normas que se refieren al derecho fundamental de la inviolabilidad del domicilio no admite duda. Así se deduce de una 
manera evidente del artículo 53,2, que ofrece la tutela de ese derecho a cualquier ciudadano que la recabe. En consecuencia, la función atribuida a los Jueces de dictar la resolución oportuna en los casos pertinentes tiene efectos inmediatos, y ello también con el doble carácter de derecho, facultad o competencia y de obligación.

Sabemos que la legislación sólo regula algunos de los supuestos en que ha de producirse la resolución judicial y que, incluso en esos casos; la regulación es incompleta y carece de un sistema armónico. Pero también sabemos que si la existencia de lagunas es lo normal en la legislación, éstas se cubren y desaparecen al completarse con las demás fuentes del Ordenamiento jurídico, que, por naturaleza, constituye un todo acabado y perfecto, en el que son inconcebibles los vacíos jurídicos. Esto quiere decir que podrán surgir dificultades para hallar la fuente jurídica adecuada y para su interpretación -de ello trataremos a continuación-, pero que, desde que la Constitución entró en vigor, la Administración está obligada, en todos los supuestos en que se le haya atribuido una función y no esté autofacultada para entrar en el domicilio de una persona, a solicitar la correspondiente autorización a los Jueces y éstos a dictar la resolución procedente.

El artículo 117, 4, de la Constitución no se opone a cuanto llevamos dicho; antes bien, lo confirma, al ampliar las funciones propiamente jurisdiccionales de los Juzgados y Tribunales a las que expresamente les sean atribuidas por ley «en garantía de cualquier derecho", que es lo que ha hecho el artículo 18, 2.

\section{ORganos Judiciales Competentes}

Los preceptos relacionados en III, $1,3 .^{\circ}$, y transcritos en el Anexo final, distribuyen la competencia de la forma siguiente:

a) En la Ley de Enjuiciamiento criminal, al Juez o Tribunal que conociere de la causa (sin duda alguna, la causa ha de ser previa).

b) En la Ley 230/63 y el Decreto 3154/68, a los Jueces de paz, comarcales o municipales (hoy refundidos los dos últimos en los de distrito) del domicilio de los deudores. En el caso de que existan varios Jueces municipales, la solicitud se formulará ante el Decano.

En los supuestos de que aquéllos no concedan la autorización, lo harán los Jueces de primera instancia.

c) En el Decreto 2166/64, a los Jueces de instrucción y, en su defecto, a los municipales, comarcales o de paz. 
Ante las diferentes soluciones reseñadas, y mientras se instaura definitivamente el nuevo sistema establecido en la Ley Orgánica número 5, de 16 de noviembre de 1981 (en que la categoría de Juez consta de dos grados: de ascenso y de ingreso), para el supuesto de ausencia de normas concretas, nos inclinamos por dar preferencia, cuando existan, a los Jueces de primera instancia e instrucción del domicilio de los deudores, porque, como señala GuASP (1), la regla general, implícita en nuestro Derecho, es que los casos no exceptuados se confíen jerárquicamente a este grado judicial y, además -agregamos nosotros-, por la especial gravedad de la materia.

En el supuesto de que existan varios, la solicitud debe dirigirse al Decano.

\section{PROCEDimiento JUdicial}

a) La Ley de Enjuiciamiento criminal no señala ninguno expresamente.

b) Según la Ley 230/63 y el Decreto 3154, los Recaudadores deberán solicitarlo y exhibir los títulos ejecutivos, y los Jueces otorgarán la autorización en el plazo de veinticuatro horas.

c) El Decreto 2166/64 también exige la petición, en la que se consignarán las circunstancias que indica. Los Jueces procederán sumariamente (diligencias indeterminadas) y su resolución será motivada.

Para los supuestos en que falte regulación concreta nos parece que lo más acertado será seguir un procedimiento similar al previsto en el Decreto 2166/64. El solicitante debe aportar certificación del expediente del que se deduzca la procedencia de la autorización del Juez, y éste puede ordenar la práctica de las diligencias previas que estime oportunas en cada caso -incluso la audiencia del afectado- antes de resolver.

\section{NATURALEZA, OBLIGATORIEDAD Y SENTIDO DE LA RESOLUCIÓN}

a) La Ley de Enjuiciamiento criminal dice que el Juez o Tribunal podrá «decretar» y que el «auto» será siempre fundado (artículos 546 y 558).

(1) Derecho Procesal Civil, ed. 1968, tomo primero, pág. 130 (2: reimpresión, Madrid, 1977). 
b) Según la Ley $230 / 63$ y el Decreto $3154 / 68$, los Jueces «autorizarán», «otorgarán o concederán la autorización», «autorizarán en las relaciones comprensivas de varias certificaciones de descubierto apremiadas", etc.

c) En el Decreto $2166 / 64$ se dice que «en el otorgamiento de la autorización» las autoridades competentes «procederán sumariamente» y que «la resolución habrá de ser siempre motivada».

En la práctica, conocemos resoluciones en que los Jueces que las han dictado las han calificado de auto, providencia o mandamiento judicial.

En nuestra opinión, las autorizaciones que otorguen los Jueces, a petición de autoridades gubernativas, para que se entre en domicilio ajeno, para ejecutar acuerdos administrativos, serán resoluciones judiciales por su autor, pero administrativas por su materia o contenido. Desde luego, no pertenecen al Derecho administrativo, pues el cargo imprime carácter al acto.

Por lo demás, el artículo 40,3), 2. ${ }^{\circ}$, del Decreto 2166/64 habla de Jueces de «instrucción», y el artículo 103, 4, del Decreto 3154/68, de los de "primera instancia", lo que prueba que el contenido de la resolución ni es civil, ni penal, sino administrativo, lo cual ha conducido al uso indistinto de Juez de primera instancia o de instrucción, lo que no habría ocurrdo si la materia se hubiera visto como civil o penal.

Es clara la obligación de resolver en todos los casos en que se produzca una petición, según se ha dicho antes.

Sin embargo, a pesar de que en algunos, por las expresiones literales, pareciera poder deducirse a primera vista otra cosa, es evidente que si, a juicio de quien deba resolver, no procede la autorización, tendrá que denegarla.

La resolución habrá de ser motivada.

\section{RECURSOS Y OTROS REMEDIOS}

En nuestra opinión, contra la resolución judicial que deniegue o autorice la entrada en el domicilio ajeno no cabe ningún recurso. No es tal la nueva solicitud al Juez de primera instancia que prevé el artículo 103, 4, del Decreto 3154/68, para los casos en que los de paz, comarcales o municipales no hayan resuelto o lo hayan hecho denegando la dirigida anteriormente a ellos. 
En este mismo precepto se ordena al Juez de primera instancia que ponga los hechos en conocimiento del Fiscal de la Audiencia, y el artículo 121 de la Constitución señala que «los daños causados por error judicial, así como los que sean consecuencia del funcionamiento anormal de la Administración de Justicia, darán derecho a una indemnización a cargo del Estado, conforme a la ley».

Una aclaración. Cuando hemos dicho que contra la resolución judicial no cabía ningún recurso nos referíamos a los ordinarios. ¿Cabe el recurso de amparo? Aunque el artículo 44 de la Ley Orgánica número 2, de 3 de octubre de 1979, parece requerir siempre la existencia de un proceso judicial previo, en nuestra opinión, contra la resolución que conceda la autorización para la entrada en el domicilio de una persona debe admitirse el recurso de amparo.

La Administración requirente, si el Juez se declarase incompetente, podría plantear, a su vez, una cuestión de competencia, de conformidad con lo establecido en la Ley de Conflictos jurisdiccionales de 17 de julio de 1948.

Evidentemente, habrá que dudar mucho de la eficacia de algunas de esas medidas, al menos respecto a los casos concretos que se discutan; pero siempre servirán para fijar doctrina.

\section{RESPONSABILIDADES DERIVADAS DE LA VIOLACION DEL DOMICILIO AJENO}

El domicilio es inviolable (art. 18, 2, de la Constitución). Es la enunciación de un principio; es la proclamación de la garantía constitucional de un derecho fundamental de las personas. La Constitución, en diversos artículos, delimita el contenido de este principio, señalando los requisitos que han de concurrir para que la entrada en el domicilio de otro no constituya una violación de su morada o encomendando a las Cortes Generales que aprueben las leyes que lo desarrollen y concreten, pero siempre dentro del marco constitucional.

Si se aprueba una ley que se oponga a las normas explícitas o implícitas de la Constitución, será «ilegal»; si se adopta un acuerdo o se realiza un acto contrario a la Constitución, será igualmente ilegal. Esas leyes y esos acuerdos y actos estarán configurados dentro de un tipo de ilícito, el constitucional, y, por tanto, serán nulos. Pero, al mismo tiempo, sus autores pueden estar incidiendo con su conducta en otros tipos de ilícito, penal, administrativo, civil, laboral, 
etcétera, $y$, en consecuencia, en cada caso, incurrirán en las responsabilidades que las respectivas leyes establezcan.

\section{RESPONSABILIDAD PENAL}

Lo primero que ha de quedar claro es que la violación del domicilio desde el punto de vista constitucional no supone $\longrightarrow$ no tiene que suponer- necesariamente un ilícito penal.

$\mathrm{Ni}$ siquiera todo ilícito penal tiene que ser por fuerza un ilícito constitucional. Lo que no cabe concebir es la validez y vigencia de leyes penales (ni de otro orden) anticonstitucionales. Serían leyes penales anticonstitucionales las que tipificaran como delitos y castigaran con penas conductas que la Constitución impusiera o simplemente reconociera como legítimas en todo caso.

En principio, la Constitución no ha derogado ni modificado ininguno de los preceptos del Código penal que tratan de la violación del domicilio.

Continúan vigentes en sus antiguos términos:

1. En la sección que trata de los delitos cometidos por los funcionarios públicos contra el ejercicio de los derechos de la persona reconocidos por las leyes, el artículo 191, 1, que pena al «funcionario público que, no siendo autoridad judicial, entrare en el domicilio de un súbdito español sin su consentimiento, fuera de los casos permitidos por las leyes».

2. Cuando regula el allanamiento de morada, el artículo 490, que castiga al "particular que entrare en morada ajena contra la voluntad, expresa o tácita, de su morador».

3. También, aunque esto no es exclusivo de la violación del domicilio, entre las circunstancias que eximen de la responsabilidad criminal, el artículo $8 .^{\circ}$, número 11 , aplicable al que "obra en cumplimiento de un deber o el ejercicio legítimo de un derecho, oficio o cargo».

Sin embargo, actuaciones que antes de la Constitución de 1978 eran perfectamente legales se han convertido en delictivas. Repetimos, todo ello sin que se haya modificado el Código penal. La explicación es fácil. La nueva Constitución ha derogado varias leyes que permitían a las autoridades gubernativas y a sus agentes la entrada en el domicilio de las personas sin autorización judicial. Con funda- 
mento en esas leyes se legitimaba el proceder de dichas autoridades, que actuaban en el cumplimiento de un deber o en el ejercicio de un derecho «jurídicos». Al derogarse aquellas normas por la reciente Constitución, el cumplimiento del deber y el ejercicio del derecho han dejado de ser «jurídicos», si no se cumple con el requisito constitucional de obtener previamente la autorización judicial. En una palabra, ahora no son aplicables las eximentes que resultaban procedentes con el Fuero de los Españoles, aun sin la autorización judicial, a los supuestos en que la Constitución de 1978 exige dicho requisito para legitimarlos.

Como ejemplos de entradas en el domicilio de una persona, con el simple mandato de una autoridad gubernativa, que eran consideradas legales mientras rigió el Fuero de los Españoles, y que han devenido ilegítimas y punibles después de la Constitución de 1978, podemos reiterar los que relacionábamos en III, 2, a saber: las entradas en morada ajena por motivos de orden público, expropiación, infracción urbanística y ruina normal.

En principio, las fincas en estado de ruina inminente constituyen una amenaza de mal grave, cuyo derribo no admite demora; pero no siempre es necesario derribar. Antes de actuar habrá que contar con un informe técnico, completo, preciso, que especifique con absoluta claridad las medidas que, a juicio del informante, deben adoptarse.

En realidad, el artículo 11 de la Ley 45, de 30 de julio de 1959, de Orden Público, se refiere a situaciones muy diversas. Dice así:

«La autoridad gubernativa y sus agentes no podrán entrar en el domicilio de una persona sin su consentimiento o mandamiento judicial, salvo en los casos siguientes:

1. Cuando fueren agredidos desde él.

2. En los casos de flagrante delito, tanto para la persecución de los presuntos culpables como para la ocupación de los instrumentos y efectos del mismo y de cuanto pueda servir para su comprobación.

3. Cuando en aquél se produjeren alteraciones que perturbaren el orden.

4. $\quad$ Si fueren requeridos por sus moradores.

5. Cuando fuere necesario hacerlo para auxiliar a las personas o evitar daños inminentes y graves en las cosas.

El acta y atestado que con tal motivo se levantaren serán entregados sin dilación a la autoridad judicial competente, a los efectos 
que procedan, incluso el de corregir en su caso las extralimitaciones que se hubiesen podido cometer. De toda extralimitación cometida se dará cuenta al Gobernador civil».

Los números $1 .^{\circ}$ y $2 .^{\circ}$, ambos, parecen hacer mención de delitos flagrantes.

De los supuestos previstos en los números $3 .^{\circ}$ y $5^{\circ}$, unos podrán situarse entre los casos de grave riesgo, catástrofe o calamidad pública, a que alude el artículo 30, 4, de la Constitución, y otros no, según las circunstancias que concurran.

Entrar en el domicilio de una persona sin su consentimiento (en. cabezamiento del artículo) y, al mismo tiempo, a requerimiento de sus moradores, precisa también distinciones y matizaciones, pata evitar contradicciones y hallar la solución justa, en los supuestos del número $4 .^{\circ}$

Algo parecido podría decirse de otros casos análogos: la gravedad del mal que amenaza, la urgencia en actuar, etc., serán circunstancias decisivas a tomar en consideración.

\section{OTRAS RESPONSABILIDADES}

Afirmamos en su momento que un ilícito constitucional podía no ser un ilícito penal $y$, sin embargo, constituir otro tipo de ilícito. Esta posibilidad es perfectamente concebible y de hecho se da en nuestro Ordenamiento jurídico.

El artículo 18, 2, de la Constitución, aunque no lo dice expresamente, dada su ubicación, parece garantizar también la inviolabilidad del domicilio de los extranjeros. El artículo 191, 1, del Código penal, en cambio, sólo pena al funcionario público que entrare en el domicilio de un súbdito español. ¿Quedarán incólumes los que violen el domicilio de un extranjero, a pesar de estar prohibido por la Constitución? Desde luego que no. Con independencia de que, a los efectos pertinentes, esos actos fueran declarados nulos y se exigiera la responsabilidad patrimonial a la Administración y a los funcionarios actuantes, éstos podrían ser sometidos a un expediente disciplinario.

El artículo 6.,$g$ ), del Decreto 2088, de 16 de agosto de 1969, por el que se aprobó el Reglamento de Régimen disciplinario de los Funcionarios de la Administración civil del Estado, al tratar de las faltas disciplinarias, considera falta muy grave la conducta contraria 
a los principios del Movimiento Nacional y demás Leyes Fundamentales del Reino. En la misma línea, pero con una redacción más actualizada, el Decreto 3046, de 6 de octubre de 1977, por el que se articula parcialmente la Ley 41/1975, de Bases del Estatuto de Ré. gimen local, al regular el régimen disciplinario, en su artículo 52, $f$ ), reitera que se considerará falta muy grave la conducta contraria al Ordenamiento constitucional. La violación del domicilio lo es.

El artículo 491 del Código penal exime de la responsabilidad de esta clase al que entra en morada ajena para prestar algún servicio humanitario o a la Justicia, sin exigir mandamiento judicial previo. Si alguno de estos supuestos no encaja entre los que la Constitución considera suficientemente legitimados, se produciría un ilícito constitucional, pero no penal. Según la doctrina dominante, este artículo es aplicable solamente a los particulares. En el caso de que extendiéramos su aplicación a los funcionarios, por evolución de la Jurisprudencia o modificación de la ley, lo que no nos repugna en absoluto, nos encontraríamos con algo parecido a lo señalado antes.

Quedaría todavía por resolver la cuestión de si sería aplicable la regla de non bis in idem cuando estuviera previsto el castigo de una infracción con una pena y con una sanción disciplinaria. La doctrina más autorizada se inclina por aplicar, por analogía, la regulación establecida en el Código penal respecto al concurso de delitos o de normas (arts. 68 y 69).

Por otra parte, si los infractores fueran particulares, evidentemente no podrían incurrir en responsabilidad disciplinaria, pero sí en otro tipo de sanciones administrativas y en responsabilidad civil.

\section{PROCEDIMIENTOS LEGALES ESTABLECIDOS PARA GARANTIZAR LA INVIOLABILIDAD DEL DOMICILIO}

La Constitución de 1978 ha tratado de proteger al máximo el derecho a la inviolabilidad del domicilio propio.

El artículo 81 ha dispuesto que el desarrollo de los derechos fundamentales se lleve a cabo por medio de leyes orgánicas, cuya aprobación precisa un «quórum especial».

$\mathrm{El}$ artículo 18, 2, y los que le complementan han reducido los supuestos en que se autoriza la entrada en el domicilio de las personas sin previa resolución judicial.

En el artículo 161 se han previsto los recursos de inconstituciona- 
lidad y de amparo, y en el artículo 163 la cuestión de inconstitucionalidad.

El artículo 53, 2, asegura un procedimiento basado en los principios de preferencia y sumariedad.

En el epígrafe III nos hemos detenido en el estudio del procedimiento a seguir para obtener la autorización judicial pertinente para la entrada en domicilio ajeno, procedimiento establecido para salvaguardar su inviolabilidad. Las demás garantías que acaban de relacionarse no son propias del derecho aquí estudiado, sino de varios más y de las libertades públicas. Su estudio, por lo demás genérico, como acabamos de decir, se saldría de los límites que nos hemos fijado. No obstante, dejaremos constancia de la aprobación de dos leyes de capital importancia a nuestros efectos.

1. La Ley 62, de 26 de diciembre de 1978, de Protección jurisdiccional de los derechos fundamentales de la persona, regula los procedimientos (penal, contencioso-administrativo y civil) basados en los aludidos principios de preferencia y sumariedad y con la garantía que la presencia del Ministerio fiscal supone. El artículo $1^{\circ}$, número 2, señala que, en el ámbito de aplicación de esta Ley, queda comprendida la garantía de la inviolabilidad del domicilio, y el artículo 2. que los delitos y faltas que se cometan en esta materia serán enjuiciados por los Juzgados y Tribunales de la Jurisdicción ordinaria, siguiendo las normas de procedimiento de la Ley de Enjuiciamiento criminal, con las modificaciones - para la abreviación de trámites- señaladas para los casos en que el conocimiento y fallo corresponda a las Audiencias provinciales.

Según el artículo $5 .^{\circ}$, el plazo de tramitación de las causas sobre la materia de que aquí se trata, comprendido desde la iniciación del procedimiento hasta la sentencia, no podrá exceder de sesenta días.

2." La ya citada Ley Orgánica número 2, de 3 de octubre de 1979, del Tribunal Constitucional -especialmente los artículos $2 .^{\circ}$, uno, b), y 41 y siguientes-, permite que, una vez agotada la vía judicial pertinente, es decir, cuando la resolución sea firme, se pueda interponer el recurso de amparo ante el Tribunal Constitucional (2).

(2) Sobre la naturaleza del recurso de amparo, el Magistrado don Angel Escudero DEL CoŔral, en el voto particular que formula, en el recurso de amparo 113/80 de la Sección 1:, a la sentencia de 28 de julio de 1981 , dice que no es una nueva instancia, ni una casación o revisión, sino un procedimiento autónomo. 


\section{ANEXO}

Artículo 546 de la Ley de Enjuiciamiento criminal:

«El Juez o Tribunal que conociere de la causa podrá decretar la entrada y registro, de día o de noche, en todos los edificios y lugares públicos, sea cualquiera el territorio en que radiquen, cuando hubiere indicios de encontrarse allí el procesado o efectos o instrumentos del delito, o libros, papeles u otros objetos que puedan servir para su descubrimiento y comprobación".

\section{Artículo 130 de la Ley 230/63. Ley General Trributaria:}

«Previa exhibición del documento acreditativo del crédito tributario o, en su caso, de la relación de deudores debidamente providenciados de apremio, los Jueces de paz, comarcales o municipales, según sea el que exista en cada localidad, autorizarán, dentro de las veinticuatro horas siguientes a la solicitud, la entrada del Recaudador en el domicilio de los deudores responsables».

Artículo 103 del Decreto 3154, de 14 de noviembre de 1968, por el que se aprueba el Reglamento General de Recaudación de Contribuciones e Impuestos:

«Autorización judicial para la entrada en el domicilio del deudor.

1. Exhibiendo los correspondientes títulos ejecutivos, los Recaudadores solicitarán de los Jueces municipales, comarcales o de paz del domicilio de los deudores, autorización para la entrada en el domicilio de éstos.

2. Si en la población hubiera más de un Juez municipal, la solicitud se formulará ante el Decano.

3. Los Jueces requeridos deberán otorgar la autorización dentro de las veinticuatro horas siguientes a serles pedida, y si, transcurrido tal plazo, no la hubieran concedido o la denegaran, los Recaudadores remitirán a las Tesorerías de Hacienda los títulos ejecutivos $\mathrm{y}$, en su caso, las relaciones de que trata el número 5 siguiente, consignando en ellos diligencia expresiva del motivo que determina la remisión.

4. Las Tesorerías, en el supuesto anterior, darán cuenta al Delegado de Hacienda, y éste, exponiendo los motivos de su petición, solicitará del Juez de primera instancia correspondiente la autoriza- 
ción referida, que deberá ser concedida dentro de cuarenta y ocho horas, y pondrá los hechos en conocimiento del Fiscal de la Audiencia a los efectos que procedan.

5. Los Recaudadores podrán presentar relaciones comprensivas de varias certificaciones de descubierto apremiadas, acompañando los títulos ejecutivos, y los Jueces autorizarán en aquéllas la entrada en el domicilio de los deudores en ellas comprendidos».

Decreto 2166, de 16 de julio de 1964, por el que se aprueba el nuevo texto de la Ley de Contrabando:

«Artículo 40. 3) Son autoridades competentes para decretar la entrada y reconocimiento de edificios:

$1 .^{\circ}$ Los Delegados y Subdelegados de Hacienda en el territorio de su competencia, cuando la entrada y registro hayan de efectuarse en lugares que no constituyan morada o domicilio particular.

2. Los Jueces de instrucción $y$, en su defecto, los municipales, comarcales o de paz, cuando la entrada y registro hayan de verificarse en moradas o domicilios particulares o en aquellos lugares aludidos en el párrafo precedente, cuando, por razones de urgencia, les fuera solicitado el mandamiento pertinente.

Artículo 41. 1) Para que la entrada y reconocimiento de edificios sea acordada por las autoridades a quienes corresponda, conforme a lo dispuesto en el artículo anterior, es indispensable que preceda petición escrita del agente o funcionario que intente practicar el reconocimiento, en la que se consignen las causas o circunstancias que lo motivan, la infracción que se supone cometida o que se intenta cometer, local o edificio en que ha de verificarse y nombre y circunstancias de la persona que lo habite o tenga establecida en él la industria o tráfico.

2) En el otorgamiento de la autorización las autoridades a quienes corresponda concederla procederán sumariamente y aun podrán darla antes del comienzo del servicio, si bien deberán expresar el de que se trate y determinarán el o los locales que hayan de ser objeto de la investigación.

3) La resolución habrá de ser siempre motivada, y de la misma se facilitará testimonio al funcionario o agente que hubiere solicitado la autorización». 
REVISTA

DE

\section{CRONICAS}


REVL-1982, núm. 216. PLAZA ARRIMADAS, LORENZO. LA INVIOLABILIDAD DEL DOMICILIO.

REVL-1982, núm. 216. PLAZA ARRIMADAS, LORENZO. LA INVIOLABILIDAD DEL DOMICILIO. 